\title{
FALAS DE SECA, SILENCIOS DA LIBERDADE'
}

\author{
Fábio Gutemberg Ramos B. de Sousa*
}

\begin{abstract}
"Olhe, se num existisse seca, nós, nós seria feliz. Nós com a seca fica pior, viu? Ainda aumenta mais o nosso aperreio, entendeu? Porque nós somos liberto na nossa terra como se diz, mas com seca nós somos escravos dela... e nós deixa nossa terra, como já the falei mais de uma vez, pra ir trabalhar pra os outros. Quer dizer que, invés da gente tá bem, tamos mal, tamos bem mal, num é bem. Seca só causa isso ai que eu tô the falando. É...". (fillho de pequeno proprietário que mora na terra do pai).
\end{abstract}

Falas como essa nos acompanharam em todo o periodo da pesquisa de campo. Os primeiros contatos. As conversas informais. As entrevistas, as caminhadas. Tudo que se fazia na zona rural do Cariri Paraibano desembocava em lembranças e referências à seca. E o mundo do camponês era desenhado por falas e expressóes como se fora

'Esse texto é uma reprodução revisada da conclusão da dissertação apresentada ao Mestrado em Sociologia da UFPB - Campus II, em novembro de 1992. A pesquisa a que nos referimos no texto foi realizada em duas comunidades rurais do município de Sumé, Cariri paraibano entre 1990-1991, e contou com o auxilio da INTERAMERICAN/ANPOCS.

*O autor é professor do Departamento de História e Geografia da UFPB, Campus II. Mestre em Sociologia. 
uma imagem estranha, dificil, seca, estéril, que em certos momentos passava a ser associada a tempos longínquos que a memória popular não quer que retornem, por ser um tempo "perigoso" como a seca, tempo de sujeição, tempo da escravidão, "somos escravos dela...".

Mas a aproximação da seca com a escravidão, embora tenha significados simbólicos e estratégicos bastante claros, não é o aspecto mais presente no discurso camponês. É uma forma extrema e provocante de se mostrar e denunciar uma histórica e remota situação de falta, de carência, dé insegurança, de medo. Nesse sentido, é parte de um discurso com muitos outros significados.

A seca deixa marcas profundas nas falas, lembranças, histórias e expressões, dando ao discurso camponês um sentido peculiar; transformando-o em algo seco e áspero como o próprio tempo, como a própria vida, como as pessoas e a terra.

Mas, ao mesmo tempo que é incorporada ao universo e práticas do dia a dia, a seca provoca mudanças na vida dos camponeses e essas mudanças dão outros "sentidos" ao discurso camponês (Albuquerque Jr., 1987).

Um dos sentidos que esse discurso tem assumido está intrin secamente ligado à própria história sócio-política da seca, que no seu processo de instituição foi adquirindo proporções incontroláveis, se transformando em um fenômeno que ultrapassa em muito o seu caráter natural, ajudando, inclusive, na construção de uma identidade para o Nordeste, que transcende as fronteiras da "região" e do país.

A construção de um discurso em torno da seca no Nordeste teve também a participação dos trabalhadores "pobres" do campo (é o que nos mostra Albuquerque Jr., 1987, no capítulo intitulado "A Poesia do Sol - O discurso popular sobre a seca"), que terminam reutilizandoo na perspectiva de angariar apoios e atenção para a superação de problemas seculares como a fome, a miséria, a dependência e o abandono pelos poderes públicos, ou problemas que têm se intensificado 
mais recentemente (como o monopólio da terra ${ }^{2}$ ), que não são causados exclusivamente pela seca, embora encontrem nesses momentos tendências a intensificação.

$\mathrm{O}$ discurso camponês, então, assume esse caráter de denúncia e vai redefinindo o significado da seca, que adquire ares diferentes (embora nunca deixe de ser ares quentes e secos) e serve também como justificativa para os saques (ou "ataques", como são mais comumente denominados em Pau Darco), outra forma dos camponeses aparecerem na cena pública, nas cidades nordesíinas,

"A seca é o espetáculo da pobreza em sua dimensão ostensiva e rebelde, em que se configuram os vários modos dos camponeses mostrarem sua tragédia. Organizados ou não, eles percorrem os espaços legais e ilegais, trazendo a público na cidade a situação de vida no campo". (César Barreira, 1990:78).

Esse é um dos sentidos que tem o discurso camponês em uma região fortemente marcada por estiagens. Registramo-lo por ser uma

${ }^{2}$ Um dos recursos utilizados para o aumento do monopólio da terra no Nordeste nos foi relatado por um habitante de Pau Darco:

"... que nós tinhas um terreno, que esse terreno tá prá escriturá lá... eu num sei nem por onde é, mas diz que tá tanto assim! (expressão com os dedos demonstrando tamanho pequeno). O rico ia hoje, botava fogo numa cerca, sabe? Caia uma pastagem, fazia com que a pastagem pegasse fogo, aí a pastagem queimava aquela cerca. Quando ele ia fazer a cerca, aumentava 5 braças mais pra cima, e a terra dele ficando maior, e lá vai, e lá vai... nós fícamos com 4 quadros de terra e ele ficou com grande propriedade, com uma grande..." 
forma impar que assume em alguns momentos, mesmo não sendo objetivo de nosso trabalho analisá-lo ${ }^{3}$.

Essa característica do discurso camponês, manifesta através de ações coletivas nas sedes municipais ou em seus distritos, tem um significado diverso embora complementar do aspecto que vimos anteriormente: as constantes denúncias sobre os problemas e dificuldades enfrentados em períodos de estiagens nas regiões semi-áridas.

0 caráter de denúncia do discurso camponês anda lado a lado com outras estratégias utilizadas para enfrentar as adversidades. Relembremos as palavras de uma pequena proprietária:

"É assim seu Zé, eu sei que a gente pobre tem sofrido um bocado. Arrume pra lá seu Zé, arrume pra lá essa reforma, essa reforma... vê se sai terra pra gente trabalhar com esses homens ricos, esses deputados pra acudir essa rebera (sítio) que tá tudo se acabando de fome, tudo à mingua, tudo seco, tudo sem ganho... os pobrezinhos... faz

${ }^{3}$ Os saques, ou na linguagem corrente em Pau Darco "ataques", parecem ter um significado que ultrapassa a satisfação das necessidades imediatas do "trabalhador pobre" do campo. É o que vemos nessa fala:

"Então, aquilo ali, quando uma cidade é bem ruim, o prefeito num quer prestar serviço com ninguém... 0,0 , o deputado que... apresenta aquela cidade, é dali vizinho e num quer fazer nada por ela. Então, um ataque deixa eles bem autênti$\cos$, porque eles vão prestar contas ao presidente e o presidente chama eles no ... porque você sabe que chama mesmo e diz: mas rapaz, você mora lá vizinho, você é deputado lá, você é o prefeito lá rapaz, e você num vê a pobreza passando fome pra colocar pra mim. Porque eu era pra tá sabendo disso, rapaz! Então, agora vamos ter que pagar esse débito lá.... (...) Entendeu como é que é o negócio? Então é isso aí. É através da tática pra orientar os homens no poder. Chama-se orientação, pra eles saber que uma família carente tá morta (...)". (grifos nosso). 
pena... Tu diga: "lá numa rebera de Pau Darco, o povo... só queria que o senhor visse a seca seu governador, deputado ... acuda aquele povo, abra ali uma emergência praquele povo trabalhar..."

A presença do pesquisador, interlocutor que se interessa pelos problemas, atividades e histórias do grupo, que ouve com atenção suas falas e reivindicações, inclusive gravando-as, estimula no camponês a vontade e o interesse em falar sobre temas, pessoas e grupos que quer denunciar ou de quem se quer chamar atenção. E isto é feito com o intuito de mostrar uma situação de dificuldades e carências, mas principalmente expressa a vontade de angariar apoio e aliados para seus pleitos e reivindicações, que ultrapassam em muito as necessidades imediatas (como a "reforma", por exemplo). Isto porque, o pesquisador é visto como membro de um grupo social mais próximo dos governantes e grupos privilegiados nas relações de poder na sociedade, o que the confere o papel do mediador junto às autoridades e aos "ricos"

Esse aspecto do discurso, que aparece na literatura como tendo um sentido "estratégico" e história do grupo, na sua reprodução e sobrevivência enquanto um grupo social específico, mas não deve ser hipertrofiado, pois ao mesmo tempo que o constitui, é acompanhado por outros significados, também estratégicos, mas que o complexifica e/ou relativiza.

$\mathrm{O}$ discurso que se utiliza de formas que direta ou indiretamente. consciente ou inconscientemente, colocam para o interlocutor interesses bastante claros assume, ao mesmo tempo, um caráter defensivo, pois em alguns momentos perde seu caráter de denúncia, que é mais agressivo e passa a ser permeado por um sentido conformista e introspectivo.

Vejamos um pouco mais desse significado do discurso.

${ }^{4}$ A leitura que inspirou essas considerações foi Soares, $1981: 19-28$.

${ }^{5}$ Ver discussão que Durval Muniz de Albuquerque Jr. 1987: 1-14, faz sobre o caráter "estratégico" do discurso. 
No geral, os camponeses vivem em condições bastanic dificeis, uns em estado de "pobreza" e outros de miséria (embora existam na região os camponeses "fortes"6). Se percebe muito das causas terrenas dos problemas que enfrentam, e parte são transferidos para entidades religiosas e forças superiores que são, ao mesmo tempo, portadoras da esperança e possibilidades de dias melhores para homcns $\mathrm{c}$ mulheres que vivem em muitos sentidos à margem da sociedade.

Por isso, não é dificil encontrar pessoas que depositam $\mathrm{cm}$ uma perspectiva defensiva, ou seja, de espera, suas esperanças em um governante, que muitas vezes é visto com poderes próximos aos que têm entidades superiores ${ }^{7}$. $\mathrm{O}$ que deixa a impressão de que da mesma forma que esperam pela ajuda do "patrão", esperam pela ajuda de Deus para amenizar seus sofrimentos e pela ajuda dos governantes que podem resolver tudo, ou que "com fé em Deus vão olhar pra o homem do campo".

${ }^{6} \dot{E}$ o termo que utilizam para designar pequenos proprietários que vivem em melhores condições: não precisam trabalhar no "alugado" nem no "carvão", criam gado e raramente se desfazem dele, mesmo em épocas de seca; em algumas épocas do ano "pagam serviço no alugado" etc.

${ }^{7} \mathrm{Na}$ área em que pesquisamos é bastante forte a idéia de que o Presidente tem poderes extraordinários e acima da socicdade e das classes sociais. É comum entre algumas pessoas a idćia biblica de que o Presidente (que em algumas falas mais parece um rei) é um enviado de Deus na terra. É o que vemos nessa fala:

"Porque olhe, o causo que Ele (Jesus) disse que nós tem de ter rei na corte, nem que seja 24 horas, nem que o sangue dê no joelho. O que é o sangue dá no joelho? É uma grande guerra, num é? Apois pronto, Jesus deixou escrito que quando fosse... que tinha pelos fins das eras, tinha de entrar rei na corte. Embora que fosse 24 horas. Embora que o sangue desse no meio da canela ou do joelho..." 
É um tipo de resistência que vai sendo minada até o ponto em que se perde a esperança e o que resta a fazer ć esperar pelo próximo inverno e torcer para que "Deus mande chuva".

Após recorrer a Deus no céu. que pode mandar a chuva, a fartura e com cla "a bonança". "um ano de liberdade", aos homens na terra. que podem mandar a "emergência", perfurar poços ou encontrar uma saída. Após fazer tudo isso c não ver suas expectativas atendidas, retira-se o crédito nos homens ("politicos" e governantes) e resigna-se com a pouca benevolência de Deus que não mandou chuva nem melhoras. E tudo isso termina por contribuir para a construção de um arcabouço de resistência para "tirar até o próximo inverno", que chamariamos de resistência defensiva. Isto porque em alguns momentos se incorpora as dificuldades de forma "defensiva" e passa-se a conviver com elas como se fossem algo natural, passageiro e costumeiro. Nesses momentos, são mais freqüentes expressões como "sempre foi assim", e "só Deus pode dar jeito". E a "pobreza" e a miséria passam a ser vividas com uma certa resignação ou, ao contrário, são enfrentadas se desfazendo do "chefe" da família ou de filhos que se deslocam para trabalhar $\mathrm{cm}$ áreas próximas, ou mesmo em regiões distantes como o Sudeste, o Ccntro-Oeste e o Sul do país.

Nas falas camponesas são diferentes as idéias em que o homem do campo aparece como autor de pressões para ver atendidas suas reivindicações; é diferente o reconhecer em si próprio poder para exigir dos governantes maior atenção, melhores condições de vida para 0 homem do campo e tem-se a impressão de que o final se resume à percepção de uma impotência que se transforma em falas e atitudes que misturam estratégias diversas, denúncias e conformismo ${ }^{8}$.

${ }^{8} \mathrm{~A}$ utilização em menor quantidade de mecanismos coletivos de pressão, ao nosso ver, significa mais do que "incapacidade" ou "inconsciência" por parte dos camponeses. Alternativamente certas práticas e resistência podem ser compreendidas como formas diferentes de manifestar suas insatisfações e de "pressionar" as autoridades etc. 
Esses são momentos em que as falas de "liberdade" são mais relativizadas e em que aparece (como se fora um paradoxo) com muito mais força um discurso de desespero, descrédito, desesperança. Momentos em que para alguns a "liberdade" e autonomia de viver "no seu", de ser proprietário de terra parece ver seu significado redefinido e em que o campo com a seca se aproxima mais de uma "prisão" da qual não é fácil fugir, pois "o pobre não tem pra onde ir".

$\mathrm{O}$ aprofundamento da compreensão do significado que tem a terra para o camponês dos momentos de seca, nos mostraria ainda que a "prisão" a que nos referimos há pouco, não nega a possibilidade de conviver com o seu contrário, a "liberdade". Paradoxo? Talvez, mas e por que os camponeses do Cariri Paraibano não construiriam suas representações também comportando aspirações contraditórias? Não são mortais comuns? Se livraram por acaso de práticas e sentimentos que estão presentes em qualquer grupo social, e que são permeados constantemente de contradições?

De nossa parte procuramos evitar transformar os protagonistas de nossa história em meras abstrações conceituais. Por isso, o que chamamos de contradição na visão de "prisão" que comporta a "liberdade" talvez seja algo mais simples na percepção dos camponeses de Pau Darco e nós estejamos transformando-o em um paradoxo. Pois como vimos, a seca redefine mas não elimina o controle sobre o tempo, o espaço e o trabalho que o agricultor tem quando é proprietário de sua terra. Mas também ser proprietário de terra em determinados contextos não exclui a possibilidade de se sentir "proprietário escravo".

As constantes referências às dificuldades e problemas em que vive faz com que o discurso desloque para suas margens referências a outros aspectos da vida do grupo, como se este estivesse silenciando sobre aqueles. Nesse sentido, talvez se possa explicar as poucas referências espontâneas à condição de "liberto" como um "silêncio". "Silêncio" que como nos ensina Eni Orlandi (1990:50), "significa multiplamente": 
nismos mesmos de funcionamento dos diferentes processos de significação que mostram o silêncio (que os constitui) que procuramos explicitar. Vale dizer que o silêncio a que nos referimos não é visto apenas na sua "negatividade". O silêncio é. No silêncio, o sentido é. Há história no silêncio porque há sentido no silêncio". (grifos no original).

E a ausência de referências espontâneas à "liberdade", na nossa compreensão, pode ser lida também como "produção da resistência" (Eni Orlandi, 1990:52) que através do "silêncio" assume significados importantes na compreensão do discurso camponês.

Esses dois aspectos do discurso, conformismo e resistência, estão profundamente interligados e são constitutivos da vida e reprodução dos camponeses em geral. Não podem ser vistos como excludentes, afinal de contas não se resiste o tempo todo e a tudo, nem também se conforma indefinidamente. $O$ que parece mais próximo das práticas do grupo camponês pesquisado, e que o constitui (isso é muito importante), é o envolvimento com teias de poderes e grupos sociais que caminham em direções diversas, e vivem relações de poder que comportam o conformismo e a resistência.

Seria ingenuidade procurar no discurso camponês ${ }^{9}$, grupo social visto como subordinado, apenas aspectos que mostrassem indefinidamente sua resistência. Ao final do estudo, o pesquisador teria armado suas "barricadas do desejo", mas não deixaria muitas pistas para a compreensão de reprodução econômica, política e sócio-cultural do campesinato. Nessa, podemos encontrar atitudes que podem significar a aceitação de uma certa condição vista como subordinada e, ao mesmo tempo, falas que dão um sentido diferente à subordinação e

9Sobre as noções de "discurso" e "análise de discurso" remetemos a leitor aos seguintes autores: Eni P. Orlandi, 1988; Eni P. Orlandi et alii, 1989; e Dominique Maingueneau, 1989. 
tanto umas como as outras constituem o fazer-se do grupo ${ }^{10}$, Por isso, não devem ser vistas como excludentes.

Dessa ótica é que podemos compreender o "silêncio" no discurso camponês, e o silêncio não como mero conformismo nem só como resistência, mas o silêncio como fazendo parte do grupo; nas palavras de Eni Orlandi, "há história no silêncio porque há sentido no silêncio".

O importante nessa discussão, é considerarmos que as informações coletadas estão marcadas, em certo sentido, por interesses muitas vezes negados, "silêncios" significativos e estruturantes, sonhos irrealizáveis, projetos que vão sendo paulatinamente efetivados e que guardam na sua estruturação, nas redefinições que sofrem e no seu surgimento, aspectos da conformação do grupo a outras forças sociais muitas vezes irresistiveis. $\mathrm{E}$ isso tem que ser analisado sem preconceitos ou polarizações estéreis. Ao mesmo tempo, não são atitudes típicas dos camponeses ou de qualquer grupo social específico, e sim partes constitutivas de todos os grupos sociais. Outro aspecto que chama a atenção nas falas de grande parte das pessoas que protagonizaram nossa história, é a tendência em hipertrofiar certos problemas enfrentados pelo grupo. Esse aspecto do discurso termina contribuindo para a construção de visões "oficiais", cristalizações e mitos, mas também para superdimensionar um problema e elegê-lo como o principal na vida do grupo e dar um novo sentido ao mesmo, ou construir, "inventar", criar um problema para servir como referência e identidade do grupo. Ou ainda para barganhar ajuda junto a governantes e outros grupos sociais (essas "construções" e "invenções" não podem ser vistas apenas em uma perspectiva instrumental, estratégica, mas também como atitudes "não" conscientes).

$\mathrm{Na}$ nossa pesquisa, esse sentido do discurso está presente sobretudo na visão que nos passam da seca, que se amplia e se transforma na denúncia da situação precária em que vivem, na denúncia dos fazendeiros, dos "ricos" e dos "políticos". Mas também, na visão mítica

${ }^{10}$ Expressäo e noção inspiradas em Thompson, 1981 e 1987. 
que os herdeiros das terras de Pau Darco e seus descendentes têm do Sr. Manoel Divino Ferreira, personagem que segundo falas correntes tornou possivel a existência da "comunidade" de Pau Darco e da "liberdade" que seus habitantes desfrutam hoje".

Considerar aspectos diversos quando se analisa um discurso não significa de forma alguma pulverizá-lo e terminar descaracterizando-o. Ao contrário, significa tentar compreender e desvendar textos e falas na sua diversidade e complexidade. Foi o que tentamos fazer até aqui.

Feitas estas considerações, passamos para o segundo aspecto de nossas reflexões. Comecemos com essas idéias:

"Se, de um lado, tudo é político e, de outro, se tem procurado minimizar ou desprezar a importância do político, não é menos verdade que hoje é mais ou menos claro para todo intelectual que o que ele produz como conhecimento é submetido já de saida a tensões que nascem de embates que nada têm a ver com a pretensa neutralidade da ciência, mas com as relações de força que presidem um imaginário social como o nosso". (Eni Orlandi, 1990:33).

Os caminhos percorridos para a construção de nosso objeto, a coleta dos dados de campo, a organização e análise desses dados terminaram desembocando em uma construção diferente daquelas que registramos em conversas, entrevistas, histórias de vida e na convivência com os camponeses. É importante o leitor ter clareza disso para não imaginar que o que relatamos e tentamos reconstituir pode ser encon-

${ }^{11}$ Há uma tendência nas falas dos habitantes de Pau Darco (principalmente entre os familiares) em mitificarem a figura do $\mathrm{Sr}$. Manoel Divino Ferreira, ou "Mané Cacheado" como era mais conhecido. Em torno do nome de "Mané Cacheado" há várias histórias que circulam em Pau Darco e nas redondezas. Histórias em que ele aparece com o poder de se "encantar", em que consegue curar mordida de cobra e apagar o fogo através de rezas etc. 
trado na área pesquisada tal qual apresentamos aqui. As coisas não são bem assim e a nossa construção é, ao final, algo "novo" e em certo sentido diferente da realidade pesquisada, embora tenha com essa aproximações e certas coisas em comum ${ }^{12}$.

$\mathrm{Na}$ verdade, o exercício que realizamos, a forma como o fizemos e os meios que utilizamos são responsáveis por essa "distância" entre as reflexões acadêmicas e a "realidade" vivida pelos camponeses, ou a percepção que têm da "liberdade". Essa e as formas como é vivida, ou o significado com que aparece no discurso camponês, têm uma dinâmica que dificilmente os instrumentos utilizados pela academia, por mais sofisticados e renováveis que seja, conseguem acompanhar, o que é um "limite" com o qual sempre vamos conviver já que, segundo as últimas notícias que se tem no campo das ciência sociais, essa percepção antes muito questionada e colocada em dúvida por uma certa literatura, hoje se transformou em lugar comum de muitos trabalhos que surgem dentro e fora da academia ${ }^{13}$.

Essa compreensão, a nosso ver, não diminut o significado do trabalho acadêmico e termina criando no seio da academia e de outros espaços e instituições novas metodologias para se apreender de perspectivas diversas a "realidade" ou um fato histórico. E o que nos ensina Eduard P. Thompson (1981:49), nessa passagem:

"O conhecimento histórico é, pela sua natureza, (a) provisório e incompleto (mas não, por isso, inverídico), (b) seletivo (mas não, por isso, inverídico), (c) limitado e definido pelas perguntas feitas à evidência (e os conceitos que infor-

${ }^{12}$ Sobre essa discussão ver também Eduard P. Thompson, 1981 ; Luiz. E. Soares, 1981; e Sidney Chalhoub, 1990.

${ }^{13}$ Pode-se encontrar essa perspectiva, que aqui foi colocada em contraponto a uma certa leitura do marxismo, em Eduard $\mathbf{P}$. Thompson, 1981; Luiz E. Soares, 198 l; Afrânio Garcia Jr. 1989; e Sidney Chalhoub, 1990. 
mam essas perguntas), e, portanto, só 'verdadeiro' dentro do campo assim definido."

Nas palavras também provocantes de Paul Veyne, reproduzidas por Eni Orlandi,

"diante de várias perspectivas metodológicas adotadas, não se trata do mesmo objeto visto de várias perspectivas, mas de uma multiplicidade de objetos diferentes. Ou seja, as diferentes perspectivas pelas quais se observa um fato, ou acontecimento, dão origem a uma multidão de diferentes objetos de conhecimento, cada qual com suas características e propriedades". (apud Eni Orlandi, 1988, p. 15)

Quando definimos a forma que dariamos às nossas reflexões e a seqüência em que as exporiamos (exercício só concluído com o término da última versão da nossa dissertação), sabíamos que estávamos fazendo uma opção entre várias outras possíveis e que essa opção seria uma marca que identificaria o trabalho e que daria uma "cara" diferente ao material coletado em campo. Esse, após ser analisado (ou filtrado), jamais poderia ser confundido com o material "bruto", coletado. Por isso, temos certeza que o nosso "discurso camponês de liberdade" não é exatamente o discurso de "liberdade" dos camponeses de Pau Darco, mas a transformação de várias falas e atitudes de um grupo camponês em um "discurso", ou sua construção e análise enquanto tal, operada pelas mãos, valores, perspectivas teórico-metodológicas, criatividade e imaginação do pesquisador, o que o torna diferente das falas que individualmente circulam em Pau Darco.

\section{BIBLIOGRAFIA}

ALBUQUERQUE JR., Durval M. Falas de Astúcia e de Angústia: A Seca no Imaginário Nordestino. De Problema à Solução (1877-1922). Dissertação (mestrado em História) Instituto de Filosofia e Ciências Humanas, Campinas, Unicamp, 1987. (mimeo) 
BARREIRA, César. Seca: "Reprodução e Rebelião" in Revista Sociedade e Estado, Brasília, DF, vol. 4, n.2, p. 71-91, 1989.

CHALHOUB, Sidney. Visões da Liberdade. Uma História das Últimas Décadas de Escravidão na Corte. SP; Companhia das Letras, 1990.

FOUCALT, Michel. Microfisica do Poder. 7a. ed. RJ: Graal, 1979.

GARCIA JR., Afrânio R. O Sul: Caminho de Roçado. Estratégias de Reprodução Camponesa e Transformação Social. SP: Marco Zero; Brasília, DF, Ed. da UNB: MCT-CNPq, 1989.

MAINGUENEAU, Dominique. Novas Tendências em Análise de Discurso. Campinas, SP: Pontes: Ed da Unicamp, 1989.

ORLANDI, Eni P. Terra à Vista Discurso do Confronto: Vetho e Novo Mundo. SP: Cortez, Campinas, SP: Ed. da Unicamp, 1990.

ORLANDI, Eni P. Discurso e Leitura. SP Cortez; Campinas, SP: Ed. da Unicamp, 1988.

ORLANDI, Eni P. (org.) Palavra Fé, Poder. Campinas, SP: Fontes, 1987.

ORLANDI Eni P. (org.) Vozes e Contrastes. Discurso na Cidade e no Campo. SP Cortez, 1989

SOARES, Luís Eduardo Campesinato Ideologia e Política. RJ: Zahar, 1981 .

THOMPSON, Eduard P A Miséria da Teoria ou um Planetório de Erros (uma crilica ao pensamento de Althusser). RJ: Zahar, 1981.

THOMPSON, Eduard P A Formação da Classe Operária na Inglaterra 2a cd RI Paz e Terra, 1987. (vol. 1, A Arvore da liberdadc) 
VELHO, Octávio G. Capitalismo Autoritário e Campesinato. Um Estudo Comparativo a partir da Fronteira em Movimento. $2^{\mathrm{o}}$ ed. SP-RJ: Difel, 1979.

VELHO, Octávio, G O Cativeiro da Besta Fera in Religião e Sociedade, s/referências, março/1987, p. 4-27. 